\title{
WARNING
}

No part of this article may be reproduced, stored in a retrieval system, transmitted, or distributed, in any form, by any means, electronic, mechanical, photographic, or otherwise, without the prior permission of Indiana University Press.

For educational reprinting, please contact the Copyright Clearance Center (508-744-3350).

For all other permissions, please visit http://iupress.indiana.edu/rights. 


\section{Performing Age, Performing Gender}

\section{KATHLEEN WOODWARD}

How is the older female body represented in visual mass culture? Contrasting the performance of age in two recent feature films-About Schmidt and Pauline and Paulette-I draw on the strategy of Pauline and Paulette, which focuses on the older female body to the exclusion of the male body. I turn to the work of the artists Louise Bourgeois, Rachel Rosenthal, and Nettie Harris, exploring how they expose, critique, subvert, and exceed what I call "the youthful structure of the look," one that exhorts women to pass for younger once they are a "certain" age. In their work, the female body is presented boldly and bracingly as the continuing site of gender and sexuality. At stake is what I call "feminist aging."

Keywords: age autobiography / aging / feminist aging / sexuality / the youthful structure of the look

In academic and artistic circles, the body has been the locus of attention for many years, but the older female body has been significant only in terms of its absence. Consider two voluminous and important collections-The Female Body in Western Culture edited by Susan Suleiman (1986), and The Artist's Body edited by Tracey Warr (2000). In the first collection, we find not a single reference to the older female body, and in the second, only one. ${ }^{1}$ But if the invisibility of older women in academic feminism and the arts is striking, it should not be surprising. Ageism pervades American culture, and feminism in all its forms, as well as cultural studies in general, have not been exempt from it. ${ }^{2}$ With the exception of disability studies and work on illness narratives, our implicit and unexamined assumption when we make reference to the body as a category of cultural criticism is that the body is a youthful healthy body. ${ }^{3}$

We need to bring the representation of the older female body into focus, and we need to reflect on what we see and what we don't. How is the older female body represented and, more important for my purposes in this essay, performed in visual mass culture? How have older women artists performed age? What might be said to constitute feminist aging in terms of the body? How do we measure our own collusion in our culture's prejudicial conventions with regard to aging? These are large questions, and I will only be able to gesture toward some directions we might take to begin to answer them, hoping that my thoughts will prove provocative and invite further work. ${ }^{4}$ My opening touchstones will be two recent popular films-About Schmidt and Pauline and Paulette. Turning to the work of Louise Bourgeois, Rachel Rosenthal, and Nettie Harris, I will then 
explore the ways in which they exceed what I call the youthful structure of the look, which exhorts us to pass for younger once we are a "certain" age. I conclude by casting a critical look backward on my own work and my youthful ideas about aging.

\section{Old Age, Gender, and the Youthful Structure of the Look}

In our mass-mediated society, age and gender structure each other in a complex set of reverberating feedback loops, conspiring to render the older female body paradoxically both hypervisible and invisible. It would seem that the wish of our visual culture is to erase the older female body from view. The logic of the disappearing female body would seem to be this: first we see it, then we don't. Allow me to give a brief example from the world of recent popular film, beginning with the aging of the male body.

In About Schmidt, directed by Alexander Payne (2002), Jack Nicholson portrays a 66-year-old Midwestern insurance executive whose retirement at the beginning of the film sets the plot in motion. What I call the youthful structure of the look underwrites the internal dynamics of the film. Recall these two prominent instances. Early in the film, Schmidt is seen through the dismissive eyes of the callow younger executive who replaces him. At Schmidt's retirement party he offers up an empty toast and a few days later literally steers Schmidt out the door (hypocritically he had said he welcomed advice from Schmidt, who returned to his former office only to find himself turned out again). The film thus heavily underscores the fact that Schmidt has reached the social age of old age in America-the age of retirement. In American corporate culture, Schmidt is deemed old and therefore unproductive, and vice versa. Youth triumphs over age. Nicholson performs aging as decline, one of our society's most prevalent stories for both women and men. Indeed, in the film Schmidt is represented as old not only biologically (his body is slack and he has slowed down), chronologically (he is 66), and socially (he is retiring). He is also represented as old culturally (everyone else in the film who is in his age bracket seems hipper and thus younger), psychologically (he feels old to himself), and statistically (as an actuary, he is familiar with the statistics that predict the probability of a widower dying within a certain number of years of the death of his wife). In the film, these six meanings or definitions of age converge in the figure of Schmidt. ${ }^{5}$ Although we may find the cliché-driven young executive obnoxious and feel some comic sympathy for Schmidt as he is firmly retired to the sidelines and blindsided by widowhood, Schmidt is presented as clearly not having a clue.

But the comparative value of age in our society is also structured by gender. Schmidt repeats the ageist gesture to which he has been submitted in the workplace in relation to his wife at home. "Who is this old woman 
who lives in my house?" Schmidt wonders, staring at Helen, his "stout, gray-haired" wife of 42 years as she sleeps in their bed (Holden 2002, E1). Played by June Squibb, Helen is a sexless figure, a woman who hectors her husband and devotes herself to cleaning their house. Schmidt thus casts himself as younger although he and Helen are the same chronological age, replicating the reflex of our culture that women in the United States are "aged," as Margaret Gullette has memorably put it, long before men (2004). The storyline confirms this. Helen is efficiently killed off early in the film, dying unexpectedly of a blood clot to the brain (first we see her, then we don't). ${ }^{6}$ Schmidt, however, is offered an escape of sorts, one that draws on a well-honed tradition in American fiction and film. He takes to the road. He is also allowed to indulge in a sentimental fantasy of global fellow feeling (recall the implausible soliloquies Schmidt delivers through the ageinappropriate letters he writes to a 6-year-old Tanzanian orphan).

The youthful structure of the look-that is, the culturally induced tendency to degrade and reduce an older person to the prejudicial category of old age-also underwrites, I would argue, the relation of the spectator to the characters in the film. The spectator is positioned as younger and thus as superior to Schmidt (or vice versa). Steven Holden's review of Nicholson's performance in About Schmidt in the New York Times might be said to constitute an example. "Plodding in a wary, stiff-legged shuffle, his shoulders bowed, his features half-frozen into the guarded, sunken expression of someone who has devoted decades of thought to actuarial calculation, his character, Warren Schmidt," Holden writes, "is a staid Middle American everyman who finds himself adrift at the precarious age of sixty-six" (2002, E1). The implication is that Nicholson's performance of the deadened 66-year-old Schmidt is in fact realistic, commensurate with what the dreaded age of 66 will bring. Similarly, indeed with a vengeance, the spectator's relation to Helen is also characterized by the youthful structure of the look, one that is further inflected by gender. A minor one-dimensional figure, the unattractive Helen-we notice her only to forget her-is seen primarily in terms of her relation to her husband and daughter. ${ }^{7}$

Given the ageism that saturates American visual culture, my point is that in general we cast ourselves as younger in relation to the old person we see on the screen or in a photograph (as spectators we inhabit the position of an uncritical "younger than") unless, importantly, we are invited otherwise by the non-normative nature of the cultural text, or if we have educated ourselves to see past conventional and reductive ageist responses. I equate this default spectator with what might be called the ideology of American youth culture, where youth is valued at virtually all costs over age and where age is largely deemed a matter for comedy or sentimental compassion. This is precisely the case for the comedy that is About Schmidt. 
For when viewed through the lens of realism or verisimilitude, both Nicholson's performance of 66 and Squibb's performance of 66 are profoundly unpersuasive. Both deliver sitcom performances replete with banalities and bromides. They offer caricatures of the mode of embodiment of old age, a hyperbolic putting on of age, age virtually in drag but with no critical edge or theatrical pleasure in view. ${ }^{8}$ What we see in About Schmidt is mockery, not mimicry. ${ }^{9}$ At precisely the moment we are experiencing a revolution in longevity and a decrease in the rates of disability among older people, extending or postponing biological aging into the future, Nicholson and Squibb were asked to play 66 as far too old. In the characters of Schmidt and Helen, the final effect is that older age is performed in the way we would say gender might self-consciously be performed, albeit in a consistently negative register. It is something that is put on, like weight, in the case of Nicholson, or something emphasized, like a shapeless gray haircut, in the case of Squibb. Something captured in a gesture or movement, like shuffling. Something subtracted, like muscle tone. This helps us understand the veneer of impersonation in their performances. ${ }^{10}$ In About Schmidt, old age cast in the figures of Nicholson's Schmidt and Squibb's Helen is anachronistic. ${ }^{11}$ Yet, of the two, it is Helen who is offered no possibility of transcending the reductive role that the film has offered her. ${ }^{12}$

How, then, can we learn to see older women differently? Consider Pauline and Paulette, the Belgian-Dutch film directed by Lieven Debrauwer and released in 2002. Set in a village in the Dutch-speaking part of Belgium, Pauline and Paulette bears some superficial similarities to About Schmidt. The plot pivots around Pauline, played by the celebrated Belgian actress Dora van der Groen, whom one reviewer perfectly described as a "little girl of sixty-six" (Bradfer 2001). As in About Schmidt, the plot is advanced by a sudden death and a retirement. But here the similarities end. The four main characters of Pauline and Paulette are sisters in their 70 s and 60s (although one may very well be in her 50s). None of them are married (although one is living with a man).

The film's slender narrative revolves around the question of who will care for the developmentally disabled Pauline-she has the cognitive age of 6-after the sister with whom she has been living suddenly dies. Pauline adores her sister Paulette (played by the equally celebrated Ann Petersen) and wants to live with her. Paulette, who is retiring from her life as the owner of a feminine fabric shop and as a lead singer in the local amateur operetta, cannot fulfill Pauline's wish. Low-keyed and unassuming, Pauline and Paulette intercuts an aesthetic of generous realism with that of the fairytale.

Although the film is populated by older women, old age is not foregrounded as it is in About Schmidt. How to learn to care for others and to take pleasure in the small measures of everyday life constitutes the 
moral heart of the film. Difference in the guise of the disabled, not age, is its primary focus. If in About Schmidt older age in the guise of Jack Nicholson's character is cast in dismal relation to the young, here the eye of the camera is decidedly not guided solely by the youthful structure of the look..$^{13}$ Instead, throughout the film we see the sisters predominantly in relation to each other. If growing older seems virtually unnatural in the Hollywood habitat of Alexander Payne's America, in Lieven Debrauwer's modest film, set in northern provincial Europe, growing older seems on the contrary so natural that it is unremarkable, ordinary, commonplace, a part of the landscape.

Indeed the single scene in Pauline and Paulette that is structured by the blatant opposition of youth and age represents a glaring intrusion in the world of these sisters. Fittingly enough, it takes place on the stage, as if to set the all-too-banal struggle between those younger and those older apart from the pressing concerns of the three sisters. Paulette, who takes unmitigated delight in the pleasures of wigs, makeup, and gowns, has just given her last performance. Dressed in full overblown regalia, she delivers her farewell speech, oblivious to the two young and impatient women who are rolling their condescending eyes. For a moment we see her through their eyes. Yet, even as we do, given the world of Pauline and Paulette, their point of view is exposed as immature and spiteful, one that is clearly beside the point. If their derision comes as a shock to us as spectators, it is quickly understood for what it is. The spectator does not inhabit the position of the youthful structure of the look, which reduces an older person to the flat and prejudicial category of old age.

And yet in another sense, the film turns precisely on difference in age. It is however first and foremost psychic age, not the invidious oppositional visual appraisal of age by youth with its relentless focus on the body. Pauline, we are never allowed to forget, is a little girl of 66 . Her character does not represent the familiar psychological phenomenon of people feeling themselves to be younger than their chronological age (I'm 60 , but I feel 45) or exhorting themselves to be younger by dint of enthusiastic will (you are only as old as you feel). In the figure of Pauline, youth and age are not understood as irreconcilable opposites; rather they are intertwined. The figure of Pauline suggests, although it does not represent, the psychic truth that at virtually any age and as we grow older we all contain different age-selves. This is what I call psychic age, something much more difficult to perform than psychological or social or cultural or chronological age. Or, I might add, statistical age. ${ }^{14}$

About Schmidt and Pauline and Paulette are grounded in strikingly different aesthetics. About Schmidt is a combination sitcom and sentimental comedy while Pauline and Paulette draws on an aesthetic of generous realism laced with the vivid colors of a fairytale. Despite these aesthetic dissimilarities, they nevertheless do isolate for us paradigms of performing 
age we can usefully compare. In About Schmidt, performing age is principally a bodily effect anchored in visuality that structures-and is structured by-the twin force fields of the American youth-old age system and the conventional codes of masculinity and femininity that dominate the sex-gender system. Conversely, in Pauline and Paulette, the performance of older age in a world virtually emptied of youth and of men has the effect of transparence, so much so that age as a prejudicial social category and necessarily dispiriting experience ultimately seems to disappear from view as the subject of the film. Thus the film offers us a methodology for considering women performing age. Evacuate the stage or screen or photograph of youth and of men so that within the frame of performance the power of the normative youth-old age system and the sex-gender system is diminished. One possible effect is that the older female body as it is conventionally understood may first be seen for what it is and then recede or disappear from sight, allowing us to see older women differently and otherwise. ${ }^{15}$

\section{Female Artists Performing Age Otherwise}

Taking my cue from Pauline and Paulette I thus turn to fields of performance largely unpopulated by men and by youth, further narrowing my focus to the single female body in performance art. I understand, of course, that as spectators we may still find ourselves seeing through the eyes of the youthful structure of the look. But the work of these women-Louise Bourgeois, Rachel Rosenthal, Nettie Harris—challenges us in a rich variety of ways to see differently, to look beyond our culture's conventional view of the female body. Importantly, unlike June Squibb in About Schmidt or Dora van der Groen in Pauline and Paulette, they are not actresses playing older women in a narrative of someone else's making. Rather they are women presenting or performing themselves. In the case of Bourgeois, I single out one of her body sculptures. In the case of Rosenthal, a videotape adapted from a stage performance. In the case of Harris, the photographs that result from her collaboration with Donigan Cumming. In all three of these very different cases, the normative youth-old age system and sex-gender system do not frame their work, or do so only in that they seek to expose, critique, subvert, and exceed the conventions of aging for older women. Or to imagine things differently. None of them invest themselves in passing for younger, concealing their bodies in a masquerade of youth. ${ }^{16}$ Instead they display their older bodies-publicly, playfully, theatrically, flamboyantly, sardonically, ironically, and pensively, self-consciously performing age.

Consider first an arresting photograph taken in 1978 of the sculptor Louise Bourgeois (she was 67 at the time). It is a photograph that solicits a smile. Taken outside of her house in Manhattan, it shows Bourgeois 
wearing one of the body sculptures she created for the fashion show-entitled A Banquet: A Fashion Show of Body Parts-that accompanied her 1978 sculpture Confrontation (Fig. 1). Worn as a tunic, the body sculpture, crafted out of molded latex, is large and round and dented. Writer Brian Leitch, who watched the videotape of the fashion show with Louise Bourgeois in 2002, tells us what he saw: "The commentary, read fashion-show style by a former Playboy bunny, describes the action while an amusing assortment of real genitals, prosthetic naughty bits and masses of multiple breasts stride by" $(2002,160)$. His description is typical. Bourgeois's wearable art-body parts-they are suggestive of breasts and genitals, of female and male, of the primordial and the pop-have consistently been read within the context of her early life, scarred as she has often said by her father's sexual profligacy. And as a whole, her work has been largely understood as emerging out of this trauma, one revealed in its pervasive iconography of aggressive and destructive sexuality and underwritten by fear, anxiety, and anger. ${ }^{17}$

I want to frame this photograph differently, not in the context of Bourgeois's psychobiography, but prophetically in the context of advances in reproductive technology. For women, the cultural dichotomy of youth and old age has long been underwritten by the biological dividing line between the reproductive and post-reproductive years, with the symbolic date of older age for women understood as coinciding with menopause around the age of 50. But with the achievement of postmenopausal pregnancy in the 1990s (recall the 63-year-old Californian, Arcely Keh, who gave birth to a child with the aid of in vitro fertilization in 1997), the once blunt biological dividing line between premenopausal and postmenopausal women was blurred definitively. The longevity revolution acquired a new meaning. It was no longer understood only in terms of the number of years added to life expectancy. Now the longevity revolution also included the number of years that can be added via technology to a woman's body in terms of reproduction. How did our culture receive the announcements of this unexpected possibility? What were the first reactions to this news?

They might be said to have been condensed humorously in a cartoon by Ian Richardson of a pregnant grandmother featured on the cover of The New Yorker (1997). Here the figure of a pregnant woman beyond menopause is represented in terms of comic derision, one that both responds to and promotes cultural panic. As the cartoon suggests, the very association of fertility with an older female body is absurd, a cultural contradiction in terms, one that in the register of humor elicits a dismissive smile of superiority. Thus, here the conflation of the reproductive body and the post-reproductive body is presented as ridiculous, unnatural, perhaps even perverse.

Gazing in the mirror is a ubiquitous trope in the image-repertoire of age. In this cartoon the caricature of the grandmother is herself shown 


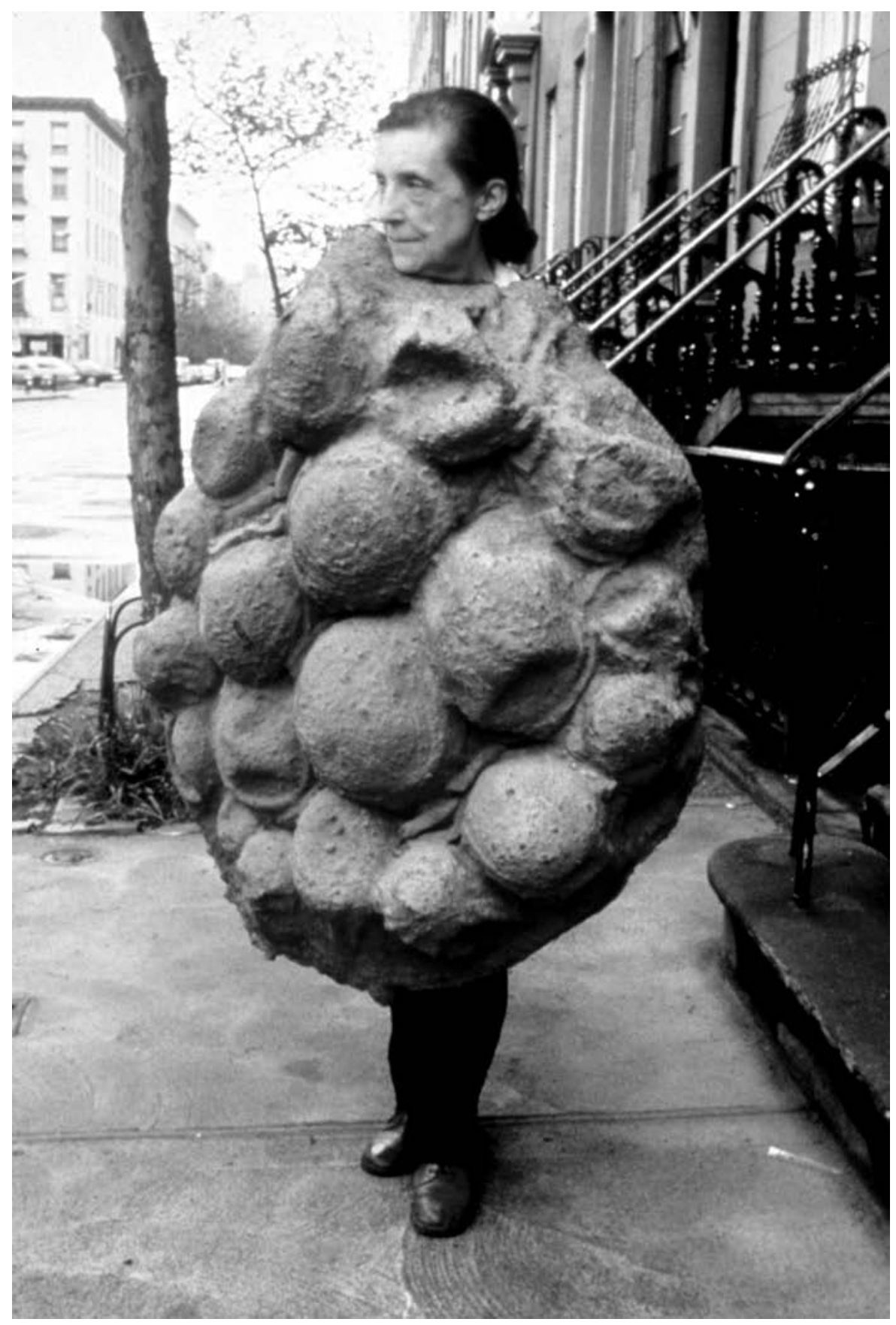

Fig. 1: Louise Bourgeois in 1975 in a latex costume designed and made by her. Photo (C) by Peter Moore 
expressing her own ambivalence. Her reaction, presented doubly, is testimony to cultural confusion. On the one hand, she seems to be pleased. On the other hand, her image gazes back at her, baffled and bewildered. Gestating a new life within an age-marked body, the figure stands as an anomaly between the polarities that inform our cultural expectations of women in terms of youth and age. This contradiction is additionally signaled by the presence of two age-related objects in the frame. On the one hand, we see a cane, a phobic object associated with the disabled body and the old body (the old body is itself often understood as a disabled body). On the other hand, we see what is called a stimobile, a psychologist-approved aid in infant stimulation introduced in the mid-1990s. If technology is available to extend and thus rewrite the plot of a woman's reproductive life, our cultural image-repertoire was not yet supple enough to accommodate these new possibilities. For is not the grandmother-the sexless and comfortable grandmother-one of the few stock images of the older woman?

The birth in Bucharest of a daughter in January 2005 to Adriana Iliescu, 66, was accompanied there by a renewal of debate over the ethics of women beyond menopause having babies, with a draft law banning fertility treatments for older women pending in the Romanian Parliament ("World Briefing" 2005). And yet this past May, the New York Times, reporting that a 57-year-old woman from Alabama had given birth to twins, did not feel it necessary to include negative commentary ("Alabama: A Mother Again at 57" 2005). On the contrary, in the Birmingham News she is quoted as remarking, "There are lots of options there for older women like me. Women shouldn't give up hope without exploring all of their options" (Gray 2005).

It is in this context that I find so marvelous the photograph of Bourgeois taken almost 30 years ago. ${ }^{18}$ Her body sculpture endows her with the shape of pregnancy. As a physician told me, it recalls an outsized ovary, one that has released many eggs. Wearing her own work with an enigmatic Mona Lisa lightness in her look, Bourgeois performs age differently, modeling the polarities that inform our cultural expectations of women in terms of youth and age and transmuting them in the process, presenting a creative female body that is not post-reproductive but productive, a new kind of female body in older age, one that is in fact appearing on the world stage.

Second, consider Rachel Rosenthal, a veritable force of nature. ${ }^{19}$ Her solo performance piece entitled Pangean Dreams premiered at the Santa Monica Museum of Art in 1990 when she was 64. Soon afterwards it was adapted into a videopiece. Drawing on the metaphorical equivalence of geological time with the lifespan of the human body, in Pangean Dreams, Rosenthal explores the breaking down of the individual human body through the passage of time in analogy with the breaking up of the 
continental landmass called Pangaea eons ago. In physiological and anatomical terms (this is biological or functional aging), aging is undeniably associated with a loss of function, one whose upper limit is death. In Pangean Dreams, Rosenthal confronts this limit, acknowledging that she "won't go on forever" (1990). But at the same time she concludes the piece on a note of moving, if playful transcendence. Throughout Pangean Dreams are interspersed scenes of Rosenthal as an amateur archeologist unearthing what appear to be human bones in various stagy and sandy settings. At the end of the piece, as if continental drift could be somehow reversed through science and art and the continents combined again into a single landmass, these bones come together in the shape of a human form, a body of bones.

The end of the tape is prefigured in its opening sequence, where Rosenthal performs age-as-decline in reverse. If in performing age Jack Nicholson and June Squibb put it on, Rosenthal takes it off. Imagine this. Rolling onto the stage in a wheelchair, she tells us that her body-shattering into fragments, coming apart-is not what it used to be. Her tone is vociferous, darkly ironic, weary yet strong:

1990 is the year my body broke up. Yeah. Broke up. First my wrist went. Then my thumb tendons snapped. My rib cracked. My lower back went out. My knee is in such bad shape it has to be replaced with a plastic one. I suffered twocount them-compression fractures of the vertebrae. And my immune system is fighting my neuromuscular system. A major dismemberment episode. There were times when the pain was so excruciating that I even considered [she puts her finger to her head as if to shoot herself]. ... I began to experience pain as an autonomous being. (1990)

But at the end of this opening segment, Rosenthal throws off her constraints, defiantly casts down her crutches, and announces that she refuses to be confined to a wheelchair.

Is this mere wish fulfillment? The performance of the fantasy that through the force of our will we can reverse aging as physical decline? Here biography adds substance to what might seem an empty dream. Since her 30s, Rosenthal had suffered from degenerative arthritis of her knees so brutal that it had severely limited her flexibility and caused her excruciating pain. But as a result of a series of operations in 1990 and in following years-operations on her back, on her leg, on both her right knee and her left knee-Rosenthal recovered much of her movement and left her pain behind. In fact, then, functional age-as-decline was counteracted through the skill of surgery. As Rosenthal wrote in 1994, "in my late sixties now, I feel whole, painless, and agile" (203).

How does performing age intersect here with the performance of gender? If concern with age frames Pangean Dreams, the play of gender-femininity and masculinity-is foregrounded throughout it. But gender is not 
explored in terms of contrasting difference between two figures, one male, the other female, as with Schmidt and Helen in About Schmidt. Rather masculinity and femininity are poses adopted by Rosenthal herself, with the effect that gender is also an elastic site of subjectivity. In the course of the piece, Rosenthal assumes a multitude of gendered personas ranging from gender neutrality to exotic masculinity and femininity. We see her wearing a swath of bright blue eye shadow and long dangling earrings. We see her without any makeup. We see her dressed as a rakish Frenchman complete with beret and as a Russian in period masculine garb. We see her clothed as a refugee. Costumed in shamanic-goddess gowns. Wearing work clothes. But throughout Pangean Dreams, one aspect of her physical appearance remains constant, and that is her signature bald head, a challenge to the dictates of taste and decorum prescribed for older women. It was when she turned 60, performing L.O.W. in Gaia in Milwaukee in 1986, that Rosenthal shaved her head and inscribed the number 60 upon it in red lipstick. It was during that performance, she has said, that she had the striking revelation-upon seeing an image of herself on the screen during the performance (Fig. 2) - that this was not just another mask but, as she explained in 1996 during a performance entitled Aging Between the Ears, "that this was me, that this was how I like to look" $(1999,265)$. Here the polarities of gender might be said to be condensed, with identity located in the psychic age-space of the body, both phenomenological and self-specular at the same time. As Rosenthal exclaims, "I felt absolutely right. This was the crowning moment for finding my own destiny because I felt now, ah! I look the way I should. . . . I identify with . . . me!" $(1999,265)$.

Finally, let us look at Pretty Ribbons (1996), a book of photographs taken between 1982 and 1992 by the artist Donigan Cumming of Nettie Harris, a former journalist and aspiring actress who died in October 1993, at the age of 81 . The majority of the photographs in Pretty Ribbons are of Harris in her late 70s and as she turned 80. Many of them are strong, and it is crucial to view them as a body of work collected over time and in space, not as single images, so as to gain familiarity with what I call the psychic body of Nettie Harris and to mute the shock that a single photograph-or two or three or four-might produce. We also require time to resist what might be our impulse to view the photographs as somehow embodying a conventional documentary aesthetic. Ideally we should "read" the book.

It seems undeniable that in many of the photographs Harris is performing for the photographer and has been posed by the photographer. But in others, it seems that even as she adopts a pose, she sinks into it, ultimately oblivious to the camera eye as if she were alone in the room (all but a few of the photographs are staged in interiors). In others, it seems as if she is performing for herself. What do we see when we first look at these photographs? My guess is that at first most of us see her aging body through the filter of the youthful structure of the look and thus as taboo, 


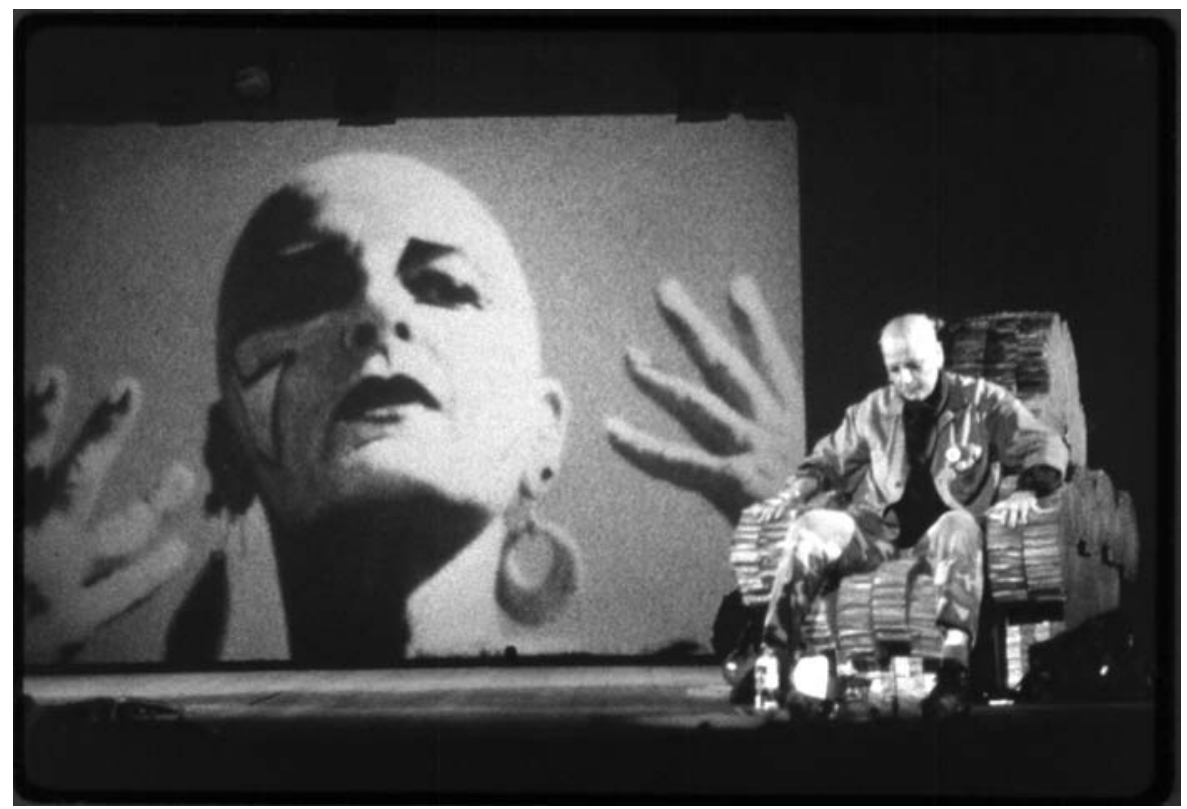

Figure 2: Rachel Rosenthal, L.O.W. in Gaia, 1986

as grotesque and naked, even somehow when clothed. ${ }^{20}$ We need to look again. We need to keep looking.

Importantly, the photographs are not arranged chronologically, refusing an order that would lead us to her death and define aging in terms of the dread of accelerated decline. Indeed one of the last photographs included in Pretty Ribbons in terms of chronological date or age-it was taken on 21 May 1992-shows us a girlish-looking Nettie Harris, 80 at the time, expressing the truth, when read in the context of the other photographs, that we are made up of different age-selves, that psychically there is no one true self defined by age but a continually fluctuating oscillation between our older selves and younger selves. Significantly, then, the photographs in Pretty Ribbons are not animated by the testimonial impulse of the documentary aesthetic (neither is Bourgeois's Fashion Show of Body Parts nor Rosenthal's Pangean Dreams). Rather I would say they represent what the French photography critic Anca Cristofovici has called speculative photography (2002). For Cristofovici, speculative photographs can "ensure the connection between the physical and the psychic self, one that eludes the rationalizations of discourse or the hierarchies of narrative. In a single vision, it brings together imaginary age-selves, not with the constancy of the phantasm but as fleeting images, like photographs themselves" (2002, 45). Thus in Cumming's photographs of Nettie Harris, what is evoked is what I call the psychic body of age (1996). Perhaps paradoxically, such 
images can have the power to disrupt the youthful structure of the look, if we allow it.

For when we look again we see not only Nettie, nude, as a placid still life, a party dress lining her back, draping her arm, her knees cradling an image of a baby. Or the naked Nettie as a grotesque clown, wearing only a turban and wielding a golf club in front of the TV that is placed in front of an improbable fireplace. Or Nettie as American gothic, her breasts bared for others to see, although she is inside with her back to the window and her eyes remain closed. Or Nettie as the dreamer of her different ageselves with multiple photographs of her face accompanying her composed sleep, evoking not so much different personas as different moments of her age-selves (Fig. 3). We also see the detritus of her surroundings, the disorder competing for attention with her body, the disheveled contents of the refrigerator containing more space in the frame than does she. Arresting and appalling as these images may be, nonetheless Pretty Ribbons does not solicit our attention as if these photographs merely mapped the abjection of poverty or decay. The figure of Nettie Harris acculturates us to the chaotic scene. The contents of these disturbing and fascinating interiors include the dirty bathtub, the radiator askew, the ratty cushions on the broken-down couch, the littered floor, and the full, black garbage bag. Yet the sheer differentiation of materials invites an aesthetic gaze in a meditative mode. There is also the sleek of satin, the panoply of beads, and the juxtaposition of fur and pressed glass (Fig. 4).

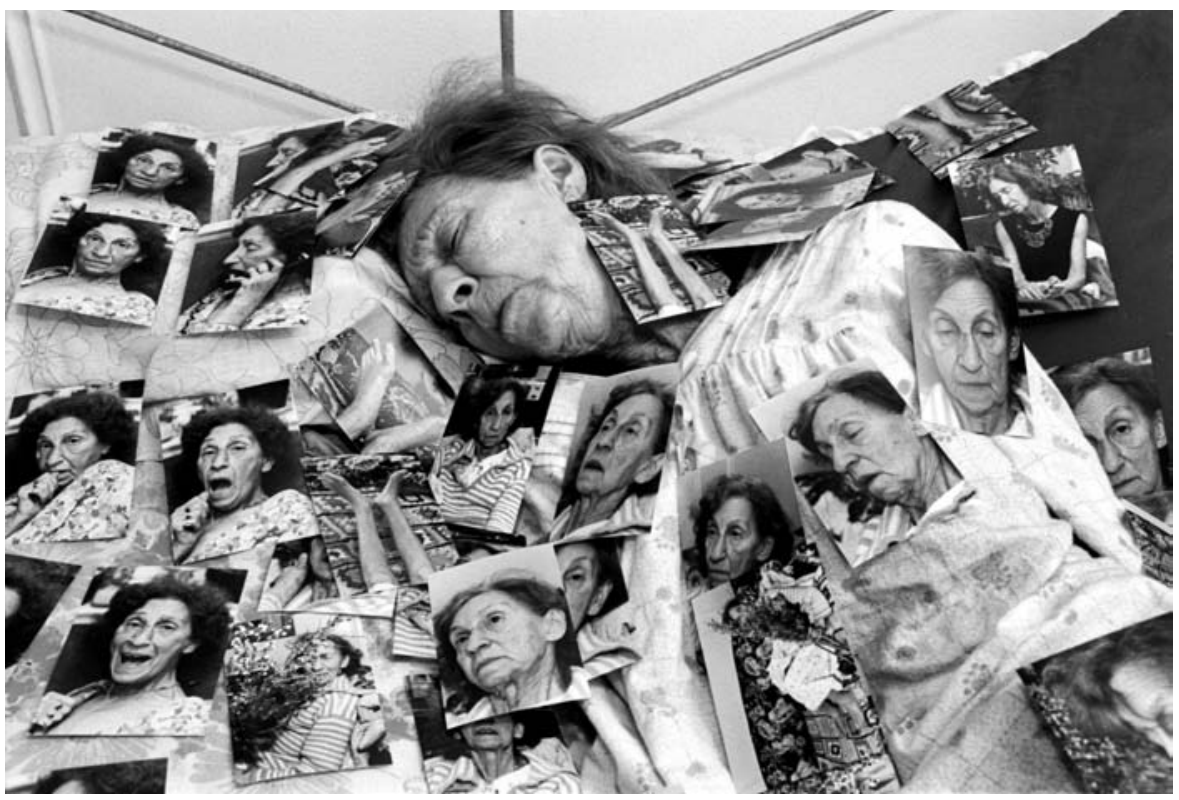

Figure 3: Donigan Cumming, May 25, 1990, 1990 from the series Pretty Ribbons 


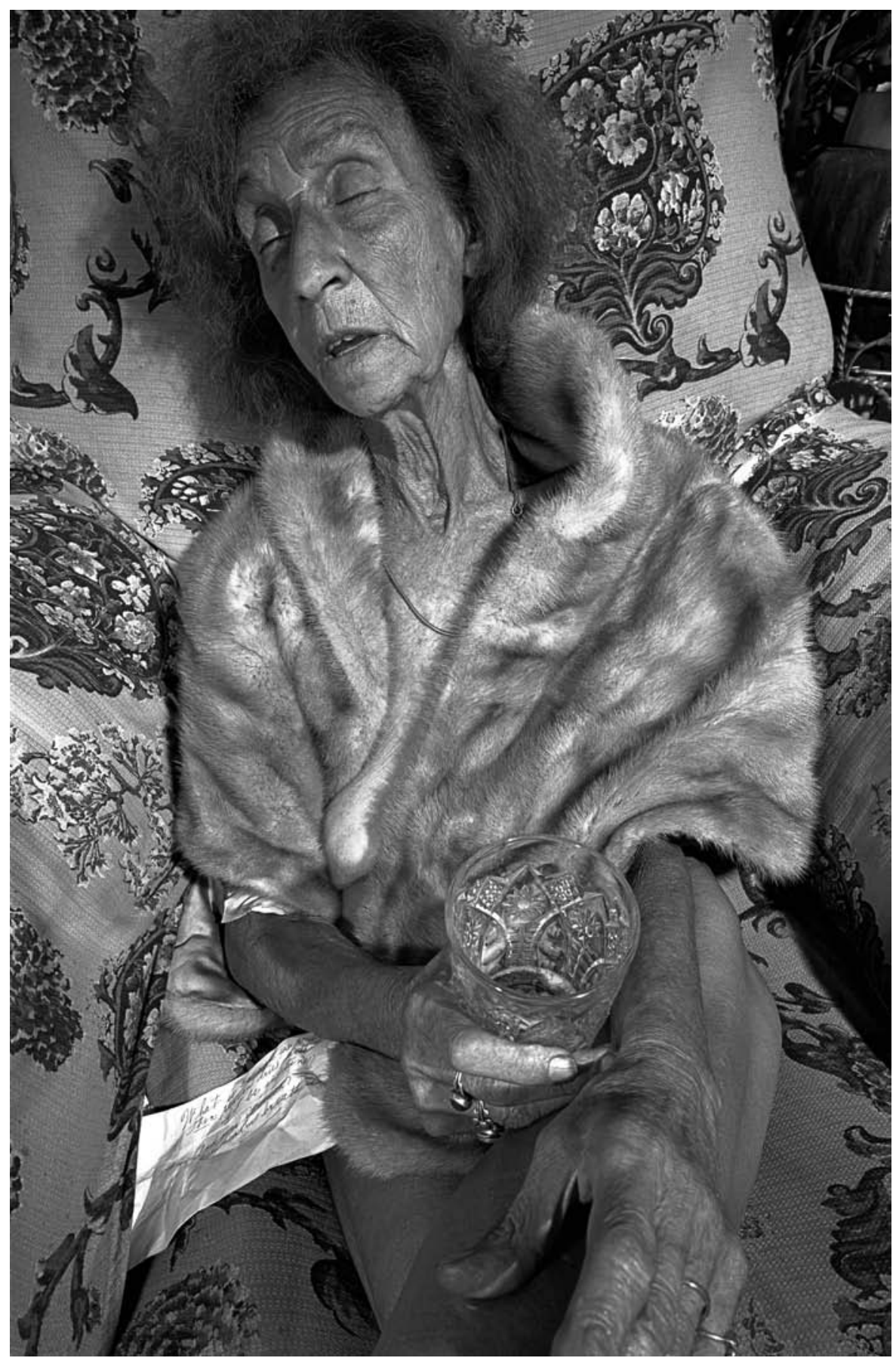

Figure 4: Donigan Cumming, July 7, 1989, 1989 from the series Pretty Ribbons 
The photographs themselves invite us to question the mise-en-scene. Poverty and older women are often equated, and yet these photographs call on us to question the reductiveness of this equation, not to merely accept them as evidence of a crushing poverty that cancels out imagination and creativity. We also see that Nettie is not the only living subject of these photographs. There is the large dog, which appears to be a staple of the frame, a close member of this psychic landscape (1996).

We also see that in only a few of the photographs, Nettie Harris is joined by male models, white and black, who are certainly younger than she is, almost all of them naked. What is the effect of this conjunction of female and male in the frame? I would say that Nettie garners the attention, and that the men recede from view, assuming less importance than does she. At the same time these are scenes that are coded sexually-the cigarettes, the leaning into one another, the intimate conjunction of bodies-and Nettie is at the center of our attention (1996).

Donigan Cumming has said that his photographs "stare," breaking the convention of looking away from aging and illness (2000). If they stare, however, they do so in a completely accepting way. The art critic Peter Schjeldahl has said of the photographer Diane Arbus that she "didn't gaze at her subjects; she induced them to gaze at her" $(2005,78)$. In many of the images Nettie Harris is not literally looking at the photographer. Yet, taken together the photographs convey an openness to the camera that is for me a certain mark of trust. There is nothing sedimented about the world of these photographs (1996). Harris and Cumming met once a week for ten years. It is clear that Harris felt the confidence and freedom to assume many different poses. She created a world that was both faithful to herself and was continually being invented. Cumming's camera-and Nettie's ongoing performance before it-encode not the normative youthful structure of the look, but the richness and constancy of Nettie Harris's psychic body, one that is youthful, playful, sexual, meditative, tired, and old, all at the same time over a long stretch of time (1996).

Thus in each of these three cases-Bourgeois and her provocative artbody part, the flamboyant Rosenthal in Pangean Dreams, and Nettie in Pretty Ribbons - the normative youthful and male structure of the look is disrupted. As performance theorist Philip Auslander has noted, in much postmodern performance the body can be understood "as a body that exposes the ideological discourses producing it" $(1990,188)$. Such performances are thus deconstructive and demystifying. But I understand the work of these three women as offering much more than that. We see age differently, if we are receptive to doing so, and enter new worlds of possibility-of the whimsical and the mischievous, of energy and edginess, of strength and courage, of mystery itself. ${ }^{21}$ Importantly, in all three of these instances of performing age, the extent to which age and gender-indeed sexuality-are inextricable is undeniable and foregrounded. A provocative 
question suggests itself. In general, at what point can it be said that age supercedes the salience of gender, filling the screen? In the crosshairs of the youthful structure of the look, I suspect that an 85-year-old, for example, will be perceived first as old and only second as a woman or a man, underscoring our culture's disbelief in the sexuality of older age.

Thus perhaps one of the most radical ways of thinking the performance of age as embodied in the work of these three women is that ultimately age as a category becomes equal to rather than more important than gender, with the body presented to us as the continuing site of gender identity. If this is the case, then I would argue that the position of the default spectator (the spectator who always understands himself as younger or more powerful) may be shifted in these fields of performance, allowing gender-and sexuality - to assume center stage.

Here I find particularly helpful an important essay on Louise Bourgeois by art historian Griselda Pollock. She argues that Bourgeois's 1996 sculpture Untitled is a pivotal piece, addressing the question of what Pollock calls "feminine ageing, or age from the diligent and fearless confrontation with its discontinuities so typical of this sculpture" $(1999,93)$. The sculpture resembles a clothes tree from whose hangers-they are made of thick old beef bones-are suspended articles of lingerie, including delicate slips and panties in white (Fig. 5). Uncannily, Bourgeois's sculpture resonates with the concluding image of Rosenthal's Pangean Dreams, in which bones are gathered together in the shape of a skeleton. But in Pangean Dreams, the daintiness of the feminine lingerie in Untitled is virtually absent and we find instead a raucous performing energy so characteristic of Rosenthal that it might be said to embody pure force, one that is channeled in the guise of strong femaleness and maleness. Much of Nettie's image-repertoire in Pretty Ribbons-a girlish cocktail ensemble, black slips, a sequined dress, multiple necklaces, earrings, and rings-also calls up Bourgeois's Untitled. In particular, I would point to the 21 November 1986 photograph of Nettie in a swimming suit, pumps, and necklace, with a feminine dress on a hanger suspended from the ceiling's light fixture (Fig. 6).

For Pollock, feminine aging is equated with the fearless confrontation of the discontinuities between the feminine (lingerie, that is, youth and sexuality) and age (bones, that is, old age) (1999). But in the bracing body work of Bourgeois, Rosenthal, and Harris, feminine aging-or better, feminist aging-need not be a contradiction in terms. Slips and bras need not signal only youth. I'll repeat this. The feminist aging body, entailing gender and sexuality as the continuing site of identity, need not be a contradiction in terms. This feminist older body is an antibody to the sexless body of About Schmidt's Helen. Moreover, it is exceedingly important that what we see in these instances is in a very real sense inimitable and cannot be reduced to a convention or a fashion or a leveling sameness. ${ }^{22}$ 


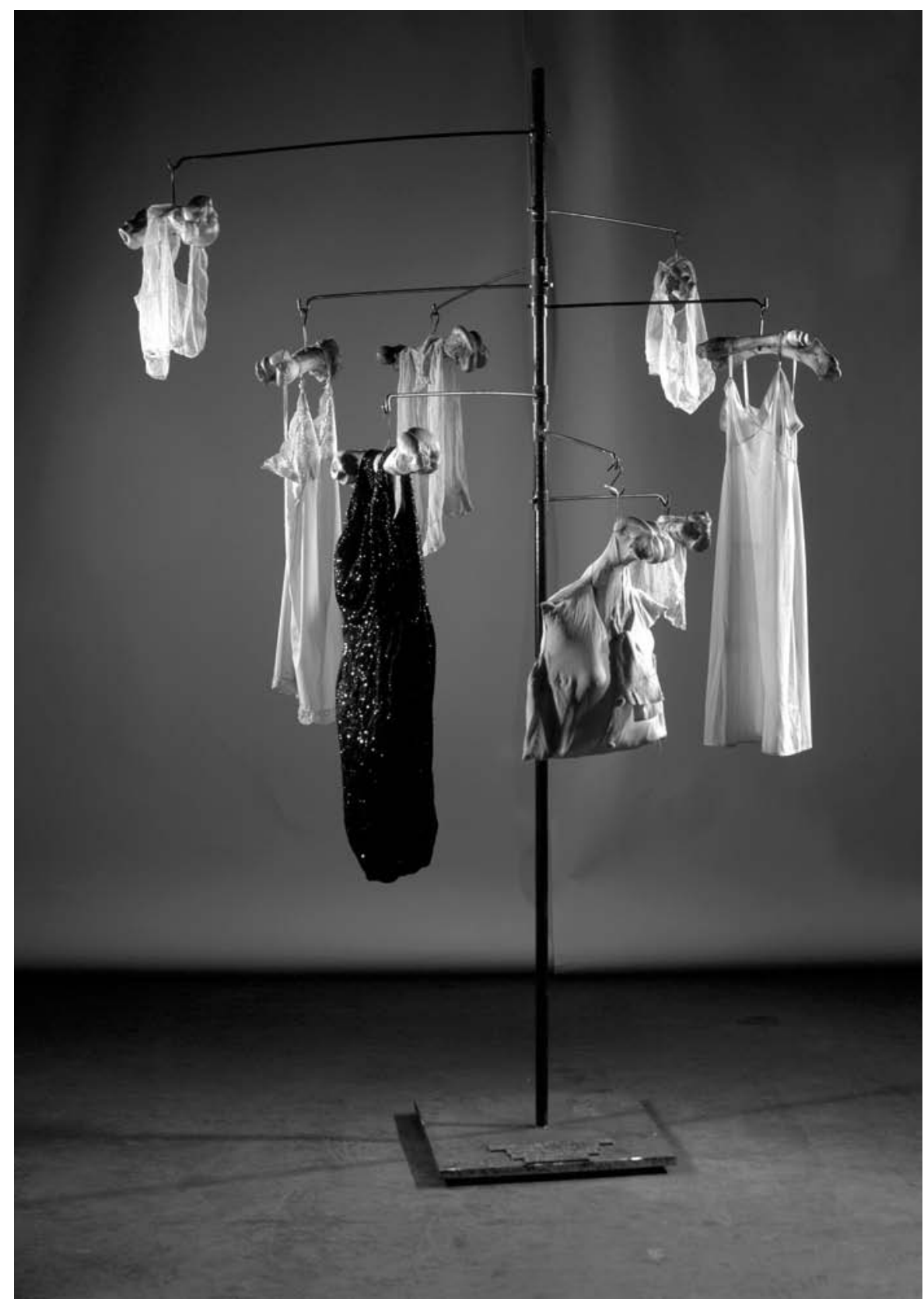

Figure 5: Louise Bourgeois, Untitled, 1996

Cloth, bone, rubber, and steel

$1181 / 4 \times 77^{\prime \prime}$

Courtesy of the Artist and Cheim \& Read, New York Photo: Allan Finkelman 


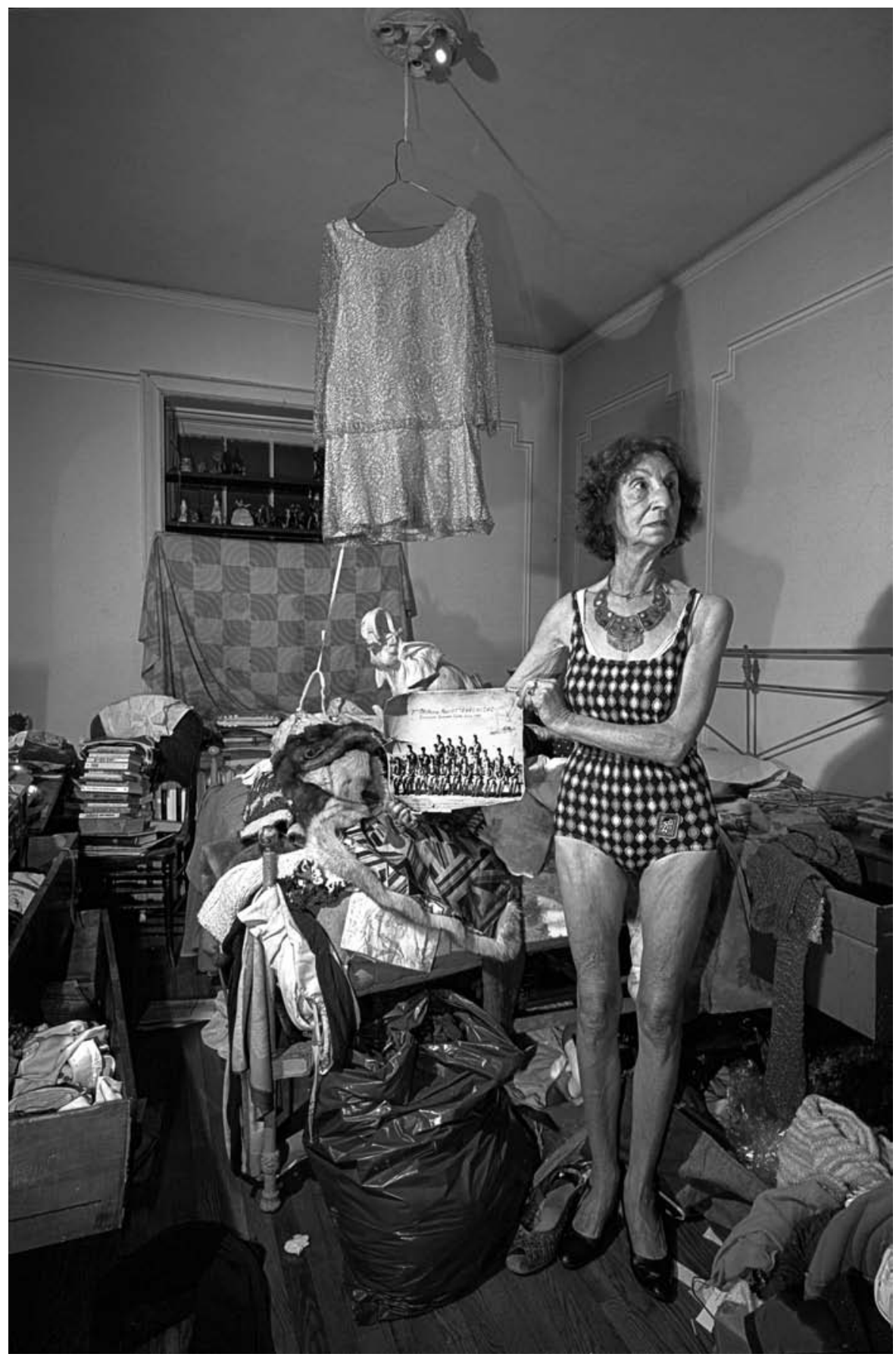

Figure 6: Donigan Cumming, November 21, 1986, 1986 from the series Pretty Ribbons 
Allow me to add a theoretical caveat here, one that is a double note of caution. I have been insisting that Bourgeois, Rosenthal, and Harris selfconsciously perform age in their work. But to what extent can they or can any of us do so? For it might be said that at certain points-moments, weeks, years - age may be located unambiguously in the data of the materiality of the body and not performed in the same self-conscious way that gender might be performed. Or to put it another way, drawing on the work of Margaret Gullette, it might be said that the body carried through time is the default body (2004). ${ }^{23}$ If gender is an identity that we accrue over time through performing certain norms that we have internalized and adopting certain practices that we take to be our own (with the two converging as the same thing), can we say that our identity in age functions in the same way? Certainly there are social and cultural norms concerning older age, conventions that all three of these women flaunt. Yet age is not a mere assemblage of such conventions. The effect of the very materiality of the body in age can be that at a certain point it performs us, reducing the latitude promised in part by the very concept of performance. Rosenthal addresses this explicitly in Pangean Dreams, tossing away the crutches that came for her with age and that, as a result of medical intervention, were no longer necessary-at least for the time being.

For the time being. . . . For we would be remiss if we did not acknowledge that in the farther future of aging, the relationships between old age, gender, and the body may take on a different valence as a weakening body may require more care and as sexuality may recede in importance. This is the important point made by sociologist Julia Twigg, who correctly observes that most of the work on the female body in critical gerontology focuses on ages 50 to 75 (2004).

\section{Age Autobiography}

How can we reflect critically on our own attitudes and ideologies of aging? For Margaret Gullette "age autobiography" is a crucial tool, one that may take the form of "a critical story of the relationship between at least two temporal selves" $(2004,153)$. At this point in time, how would I take the measure of my own attitudes toward aging? For the extent to which we can completely exempt ourselves from the uncritical position of the youthful structure of the look is very much open to question. As Julia Twigg notes, it can be exceedingly difficult to distinguish the denial of aging from the resistance to cultural conventions of aging (2004). At the same time, it can prove wonderfully instructive to turn what is now an older frame of mind on our younger selves. In such a case, older age claims authority on the basis of experience to evaluate earlier thoughts about aging, thus itself serving as an antidote to the youthful structure of the look. 
In reviewing my own work on aging, I find vestiges of sentimentalization, a privileging of a certain body politics that I no longer wish for myself-now that I am older. As I look back, I find traces of the figure of my paternal grandmother, a woman whom I adored for many reasons, not least of which is that she did so much for me and with me. Perhaps the most curious passage-it is in Aging and Its Discontents: Freud and Other Fictions-is one in which I recount a phantasmatic experience, one that was self-specular and phenomenological at the same time. I visually saw myself-and felt myself to be-in the shape of the body of my grandmother, a body larger than mine, portly in what I took to be a Victorian kind of way (1991). I was 24 at the time, and she seemed to be the age at which I remembered her being the entire time I knew her-and that was 55 or 65 (tellingly, the different numbers seemed then to me to amount to the same thing). I remember that I found "being in" her body comfortable and comforting, and I took this as a kind of psychic portent of things to come: that I would embrace the body of what I took to be a representative body of old age, finding myself at home in it. I was pleased with my vision, for I found it both reassuring and affirmative of aging, although I don't think I could have articulated this so clearly to myself then.

Today I find it quite telling that I reduced a complicated woman named Carla Jules to the figure of a grandmother-that is, a person whom I defined in relation to myself (1991). My personal view of aging at that point in time was limited in great part to identification with an older woman in the family, and today I would insist that the family must not be the limiting circle of our imagination. Today I also must confess that the prospect of inhabiting that expansive body-the grandmother's body-no longer appeals to me as it once did. On the contrary. Now I find myself being drawn to issues of Good Housekeeping while standing in line at the grocery store. "Lose Your Belly Flab-Fast!" headlines an article by Jim Karas in an April issue (2004). Inside, I learn: "It's an unfortunate female fact of life: As women age, they get thicker in the middle" $(2004,189)$. It's embarrassing-both being thicker in the middle and being concerned about it. It turns out that I agree with the reviewer of About Schmidt for the New York Times. He described Helen as "gray-haired" and "stout" (Holden 2002, E1) as was my grandmother, and I don't want to go there. It occurs to me too that when I was 24 I understood my grandmother's body as, while gendered feminine, sexless. But to quote the irrepressible Whoopi Goldberg, who puts it bluntly in the excellent Hollywood documentary Searching for Debra Winger directed by Rosanna Arquette, "Grandmothers fuck" (2002).

Aging-for ourselves individually and for all of us, no matter our age-is a feminist issue. As the founders of the Old Women's Project in San Diego declare on their t-shirts, "Old Women Are Your Future." We can take energy of many different kinds-conceptual, imaginative, creative, aesthetic, comic-from the examples of Bourgeois, Rosenthal, and 
Harris, who pointedly perform aging differently, stretching our ideas of what compelling shapes a feminist politics of the aging body may take. And they are unforgettable.

Kathleen Woodward is Professor of English at the University of Washington, where she directs the Simpson Center for the Humanities. The editor of Figuring Age: Women-Bodies-Generations and the author of Aging and Its Discontents: Freud and Other Fictions, Woodward is working on a book on the cultural politics of the emotions entitled Statistical Panic and Other Strong Feelings. She has published essays on autobiography and aging, reminiscence and the life review, and shame and wisdom. From 1995-2001 she was president of the Consortium of Humanities Centers and Institutes, and she presently serves as the chair of the national advisory board of Imagining America, an organization dedicated to artists and scholars in public life. Send correspondence to Simpson Center for the Humanities, University of Washington, Box 353710, Seattle, Washington 98195-3710;kw1@u.washington.edu.

\section{Acknowledgments}

My grateful thanks to Jeffrey Cox, Kate Cummings, Andrew Eisenberg, Mona Frederick, Elizabeth Gregory, Leni Marshall, Michelle Massé, Fran Ragsdale, Joan Schenkar, and Angela Wall, and to audiences at Vanderbilt University, the University of Colorado, Scripps College, the University of Houston and the 2005 annual meeting of the National Women's Studies Association.

\section{Notes}

1. In The Artist's Body, the single reference to the body-work of an older female artist is to Louise Bourgeois (Warr 2000); I will discuss that very piece below. The other reference is to the work of the photographer John Coplans. I might note too that the index to the recent Feminism and Visual Culture Reader, edited by Amelia Jones, contains no entries to "age" or "old" (2003).

2. For significant exceptions to this rule see, for example, Julia Twigg's essay on the intersection of old age, gender, and the body (2004).

3. Ironically, some of the important tropes that have circulated in academic feminism and in cultural studies are oddly inapposite for the older body precisely because the older body may be understood to exemplify them in prejudicial ways. For many years, for example, the tropes of the excessive body, the unruly body, the grotesque body, the uncontrollable body, the prosthetic-cyborgian 
body, and the androgynous body have been deployed as salutary. But these very tropes could be said to describe our culture's negative stereotypical notions of the aging body. As Chris Gilleard and Paul Higgs have argued, the epitome of the de-civilized body, the body the mind can no longer control, is the body under the spell of Alzheimer's disease, an aging body (2001).

4. I'm particularly concerned that the small archive I have assembled for this essay is limited to white women and trust that others will expand it.

5. Chronological age refers to the number of years a person has lived. Biological or functional age refers to the state of a person's physical capacities. A person suffering from a severe disease in middle age, for example, would be understood to be functionally older than their chronological age would normally suggest. Old age, as biological or functional age, is itself divided into categories, with advanced old age being placed at 80 , although some do place the "dividing" line at 75 , referring to the years after 75 as deep old age or the fourth age.

Social age refers to the meanings that a society accords to different categories of age, with the instruments of social policy providing clear-cut measures. In the United States, for example, the ages 62 and 65 are linked to the entitlement to receive Social Security payments on the basis of chronological age alone; the effect is that these two ages are strongly associated-indeed almost transparently so-with old age and retirement. Like social age, cultural age refers to the meanings or values that a culture assigns to different people in terms of age, but here status and power are crucial. Thus older women who are the same chronological age as men are considered to be "older" than men. Psychological age refers to a person's state of mind in terms of age. Psychologically a person may "feel" older or younger than their chronological age. Finally, by statistical age I mean predictions concerning age based on large data sets.

6. This is also the logic of consumer culture for the older woman. Hypervisible today is the older female body (and the older male body too) represented in television and print ads in the guise of the needy consumer body, which requires creams to reduce wrinkles, medications of all kinds (for arthritis and for depression), and special underwear (it is not lingerie), among other products. Not surprisingly, this older advertising body does not in fact appear very old at all, for that would threaten the very consumer who is being courted. Ultimately, the point is that this hypervisible body will disappear into the invisibility of middle age. First you see it, then you don't.

7. The film is of course more complex than this, offering us the figure of an older woman, played by Kathy Bates, whose raunchy sexual energy frightens Schmidt.

8. Much work in cultural studies has been devoted to destabilizing conventional notions of masculinity and femininity, with drag serving as a mode of performance that exposes their arbitrary nature. As Judith Butler has famously written, "drag enacts the very structure of impersonation by which any gender 
is assumed. . . Drag constitutes the mundane way in which genders are appropriated, theatricalized, worn, and done" $(1991,21)$. Derived from the tradition of female impersonation, drag also has been theorized in relation to race. See Indira Karamcheti's "Caliban in the Classroom" (1995). Here I transpose drag to the register of age.

Actually, Nicholson's performance does offer a complex pleasure to the spectator. On the one hand, Nicholson, the undeniably talented and powerful celebrity, is admired. On the other, in a display of schadenfreude, there seems to lurk some dark pleasure in his defeat. Because knowledge of Jack Nicholson the star is brought to the film, spectators can have it both ways. Nicholson the star both escapes the omnipresent pitfalls of aging in America and performs the embodiment of aging as decline.

9. I allude here to Homi Bhabha's notion of mimicry in a colonial context. Mimicry, he writes, "emerges as the representation of a difference that is itself a process of disavowal. Mimicry is, thus the sign of a double articulation; a complex strategy of reform, regulation and discipline, which 'appropriates' the Other as it visualizes power. Mimicry is also the sign of the inappropriate, however, a function of colonial power, intensifies surveillance, and poses an immanent threat to both 'normalized' knowledges and disciplinary powers" $(1994,86)$.

10. Impersonators have an odd epistemological status, as the mass cultural critic Lynne Joyrich has astutely observed (1993). They both are and are not believed. Consider Carol Channing's performance in 1995 of Dolly Levi in Broadway's Hello, Dolly!, a similar, albeit more extreme instance of the impersonation of age. At stake in this legendary case is the impersonation of middle age, with the 74-year-old Channing reprising the role she first played when she was 43 . Is it any surprise that her performance was judged in terms of her previous performance, that is, to the bodily difference-and sameness-produced by the vast difference between 43 and 74? See Anne Basting's superb essay on this subject. "By replicating the original," Basting astutely writes, "the Dolly! of 1995 isolated Channing's age as the difference between the first production and the new run, and as the challenge to her stardom" $(1999,253)$.

11. See Mary Russo's essay "Aging and the Scandal of Anachronism" (1999). At the same time, obesity and diabetes are on the alarming rise in the United States and, among other iatrogenic conditions, may cut into the trend of increasing healthy longevity.

12. There is a vast literature on performance and identity, ranging from Judith Butler's Gender Trouble (1990) and Bodies That Matter (1993) and Sue-Ellen Case's Performing Lesbian at the End of Print Culture (1996) to recent edited collections of essays, including Peggy Phelan and Jill Lane's The Ends of Performance (1998) and Amelia Jones and Andrew Stephenson's Performing the Body, Performing the Text (1999). The focus in this work is on gender, sexuality, and race. In my essay I am privileging the work that emerges out of age studies. See also Simon Bigg's essay on "Age, Gender, Narratives, and Masquerades" (2004). 
13. This is confirmed by reactions of reviewers in the popular press. Holden's review in the New York Times expresses a sentiment-it is virtually a structure of feeling-widely shared by reviewers around the country. On the one hand, Nicholson was applauded for so artfully foregoing his trademark bad-boy grin and wicked zest for life (read his youthful nature) to perform the dull old Midwesterner that is Warren Schmidt-and for doing so without apparent vanity. On the other hand, it was agreed that Nicholson, himself 65 when he filmed About Schmidt, "finally acts his age," as the words of the headline to Glenn Whipp's review in the Milwaukee Journal Sentinel sum it up (2005).

How did the reviewers understand Pauline and Paulette? Not surprisingly, in the reviews I sampled from Belgium, Canada, and the United States, age as older age was mentioned, although in Ann Hornaday's review in the Washington Post it was never even broached (2002). But age was not singled out as the preoccupation of the film, as it was in the case of About Schmidt. This is suggested by the lack of consensus on just how old the sisters are. In The Oregonian Pauline is described by Shawn Levy as a "middle-aged woman with the intelligence of a 6-year-old," in Belgium's Derniere Heure as precisely 64 (2001), and in the New York Times by A. O. Scott as in her early 70s (2002). In Toronto's National Post, Jeet Heer identifies her in the very first sentence as simply a "mentally handicapped older woman" and that is the last we read about the age of any of the characters_-or aging in general-in the entire piece (2002).

14. In MURDER and murder (1996), Yvonne Rainer may be said to perform statistical age. See my essay "Statistical Panic" for a discussion of her film (1999).

15. In drawing this comparison I do not mean to suggest, of course, that there is something inherent in popular film that prevents it from representing older women as attractive and passionate. See, for example, The Mother, starring Anne Reid as May, a widow who is involved with a younger man who is himself involved with her daughter (2003). Characterized by a realist aesthetic, the film is typically described as belonging to the genres of the drama and the romance.

16. Passing is one of the dominant forms of performing age-passing as older and passing as younger, or what I have called "youthfulness as masquerade" in analogy to the psychoanalyst Joan Riviere's analysis of femininity as masquerade (1986). For passing as older, see, for example, Nikki S. Lee's "The Seniors Project" (2001). A photographer and performance artist, the Korean-American Lee adopts the styles and practices of certain groups, "disappearing" into them as one of them. Unlike impersonation, which signals its status as performance and conveys ambiguity, passing depends on erasing the marks of performing an assumed identity.

17. Consider, for example, Jan Garden Castro's description of the body-sculptures from $A$ Banquet. "The bulges could be anything: breasts, body armor, tumors," she writes. "The multi-level image shatters the myth that breasts or lumps are nurturing, or even healthy, for the bearer or beholder" (2001). 
18. Since then Bourgeois, now in her mid-90s, has continued to produce a prodigious amount of work that has compelled international attention, ranging from the exhibition of her work at the Venice Biennale in 1993 to the award of the prestigious Wolf Prize in painting and sculpture for 2002-2003.

19. For work on Rachel Rosenthal, see Rachel Rosenthal, edited by Moira Roth (1997), and especially Bonnie Marranca's "A Cosmography of Herself" (1997).

20. Winfried Menninghaus explicitly links the figure of the older woman to disgust in his history of disgust (2003).

21. See Jodi Brooks's excellent essay "Performing Aging/Performance Crisis" in which she considers the screen performances of such actresses as Gena Rowlands and Bette Davis, arguing that in performing the two options seemingly available to their characters-refusing to abide by the conventions prescribed for older women and accepting their place in our culture's devaluation of older women—"they articulate a different sense of time" $(1999,234)$.

22. The methodology of evacuating men and youth from the field of women performing age does not of course guarantee that we will see older age differently. As a case in counterpoint, take Joyce Tennessen's book of polished portraits of beautiful older women, among them Lauren Bacall (77), Helen Gurley Brown (79), Geraldine Ferraro (67), and Coretta Scott King (74) (2002). Dressed or draped in mostly black, some costumed in white, wearing for the most part expressions of equanimity if not serenity, of poise if not beatitude, all of them seem to look alike in Tennessen's sepia-toned photographs, which betray no location and offer us no context. Entitled Wise Women: A Celebration of Their Insights, Courage, and Beauty, Tennessen's book celebrates conventional notions of femininity and suggests that these women have somehow transcended culture and time and represent wisdom, and indeed the photographs are accompanied by lofty sentiments, words spoken by the women themselves. The sentimentality we find here is vanquished in Judy Olausen's hilarious book of photographs of her 70-something mother (1996).

23. See especially Gullette's chapter "Acting Age on Stage: Age-Appropriate Casting, the Default Body, and Valuing the Property of Having an Age" in Aged by Culture, 159-78 (2004).

\section{References}

About Schmidt. 2002. Alexander Payne, director. New York: New Line Cinema. "Alabama: A Mother Again at 57, She Felt Like Dancing." 2005. New York Times, May 27, A16.

Auslander, Philip. 1990. "Vito Acconci and the Politics of the Body in Postmodern Performance." In After the Future: Postmodern Times and Places, ed. Gary Shapiro, 185-95. Albany: SUNY Press.

Basting, Anne. 1999. "Dolly Descending a Staircase: Stardom, Age, and Gender 
in Times Square." In Figuring Ages: Women-Bodies-Generations, ed. Kathleen Woodward, 248-63.

Bhabha, Homi K. 1994. The Location of Culture. New York: Routledge.

Biggs, Simon. 2004. "Age, Gender, Narratives, and Masquerades." Journal of Aging Studies 18(1):45-58.

Bradfer, Fabienne. 2001. "Entretien avec Lieven Debrauwer." Le Soir en ligne, June 27. Retrieved 20 February 2003, from http://doc.lesoir.be/scripts/\$CSHtml. exe?.

Brooks, Jodi. 1999. "Performing Aging/Performance Crisis (for Norma Desmond, Baby Jane, Margo Channing, Sister George-and Myrtle)." In Figuring Age: Women-Bodies-Generations, ed. Kathleen Woodward, 248-63.

Butler, Judith. 1993. Bodies That Matter: On the Discursive Limits of "Sex." New York: Routledge.

1990. Gender Trouble: Feminism and the Subversion of Identity. New York: Routledge.

- 1991. "Imitation and Gender Subordination." In Inside/Out: Lesbian Theories/Gay Theories, ed. Diana Fuss, 13-31. New York: Routledge.

Case, Sue-Ellen. 1996. Performing Lesbian at the End of Print Culture. Bloomington: Indiana University Press.

Castro, Jan Garden. 2001. "Louise Bourgeois: Turning Myths Inside Out." Sculpture Magazine 20(1). Retrieved 20 February 2003, from http://www.sculpture. org/documents/scmag01/janfeb01/bourg/bourg.shtml.

Cristofovici, Anca. 2002. Touching Surfaces: Four Speculations on Mutability in Art Photographs. Unpublished book.

Cumming, Donigan. 2000. "Continuité et Rupture." Hors Champ, April 30. Retrieved 27 March 2004, from http://www.horschamp.qc.ca/2004/Emulsions/ rupture-cumming.html.

—. 1996. Pretty Ribbons, ed. Hans-Michael Herzog. Zurich: Editions Stemmle.

Gilleard, Chris, and Paul Higgs. 2001. Cultures of Ageing: Self, Citizen, and the Body. New York: Prentice Hall.

Gray, Jeremy. 2005. "Great-Grandmother, 57, Gives Birth to Twins at UAB." Birmingham News, April 26. Retrieved 27 May 2005, from http://www. al.com/news/birminghamnews/index.ssf?/base/news/1116667064202480. $\mathrm{xml} \& \operatorname{coll}=2 \&$ thispage $=2 \#$ continue.

Gullette, Margaret Morganroth. 2004. Aged by Culture. Chicago: University of Chicago Press.

Heer, Jeet. 2002. "The Kindness of Sisters." National Post, 3 May.

Holden, Stephen. 2002. "An Uneasy Rider on the Road to Self-Discovery." New York Times, September 27, E1.

Hornaday, Ann. 2002. "Pauline and Paulette: Another Slice of Piety." The Washington Post, April 12, CO5.

Jones, Amelia, ed. 2003. The Feminism and Visual Culture Reader. New York: Routledge.

Jones, Amelia, and Andrew Stephenson, eds. 1999. Performing the Body, Performing the Text. London: Routledge.

Joyrich, Lynne. 1993. "Elvisophilia: Knowledge, Pleasure, and Cult of Elvis." differences 5(1):73-91.

Karamcheti, Indira. 1995. "Caliban in the Classroom." In Pedagogy: The Question 
of Impersonation, ed. Jane Gallop, 138-46. Bloomington: Indiana University Press.

Karas, Jim. 2004. "Lose Your Belly Flab-Fast!" Good Housekeeping, April, 189-90.

Lee, Nikki S. 2001. "The Seniors Project." In her Projects. New York: Distributed Art Publishers.

Leitch, Brian D. 2002. "Always on Sunday." New York Times, August 18, 160.

Levy, Shawn. 2002. "Perils of Pauline and Sister Paulette an Endearing Treat." The Oregonian, 3 May 29.

Marranca, Bonnie. 1997. "A Cosmography of Herself: The Autobiology of Rachel Rosenthal," In Rachel Rosenthal, ed. Moira Roth, 79-97. Baltimore: Johns Hopkins University Press.

Menninghaus, Winfried. 2003. Disgust: Theory and History of a Strong Sensation. Trans. Howard Eiland and Joel Golb. Albany: SUNY Press.

Mother, The. 2003. Roger Mitchell, director. CA: Columbia Tristar.

MURDER and murder. 1996. Yvonne Rainer, director. New York: Zeitgeist Films.

Olausen, Judy. 1996. Mother. New York: Penguin.

Pauline and Paulette. 2002. Lieven Debrauwer, director. New York: Sony Picture Classics.

"Pauline et Paulette: Une fillette dans un corps de 64 ans." 2001. Derniere Heure, June 6. Retrieved 20 February 2003, from http://www.dhnet.be/.

Phelan, Peggy, and Jill Lane, eds. 1998. The Ends of Performance. New York: New York University Press.

Pollock, Griselda. 1999. "Old Bones and Cocktail Dresses: Louise Bourgeois and the Question of Age." Oxford Art Journal 22(2):71-100.

Richardson, Ian. 1997. The New Yorker. Retrieved 12 May 2005 at http://www. newyorker.com/online/covers/articles/010514onco_covergallery.

Riviere, Joan. 1986. "Womanliness as a Masquerade." In Formations of Fantasy, eds. Victor Burgin, James Donald, and Cora Kaplan, 35-44. London: Methuen.

Rosenthal, Rachel. 1999. "Aging Between the Ears." In Figuring Age: Women, Bodies, Generations, ed. Kathleen Woodward, 264-7. Bloomington: Indiana University Press.

- 1997. "Rachel Rosenthal." In Rachel Rosenthal, ed. Moira Roth, 202-4. Baltimore: Johns Hopkins University Press.

—. 1994. "Rachel Rosenthal." Performing Arts Journal 46:27-9.

- 1990. Pangean Dreams: A Shamanic Journey. California: The Rachel Rosenthal Company.

Roth, Moira, ed. 1997. Rachel Rosenthal. Baltimore: Johns Hopkins University Press.

Russo, Mary. 1999. "Aging and the Scandal of Anachronism." In Figuring Age: Women-Bodies-Generations, ed. Kathleen Woodward, 20-33. Bloomington: Indiana University Press.

Schjeldahl, Peter. 2005. "Looking Back: Diane Arbus at the Met." The New Yorker, March 21, 78ff.

Scott, A. O. 2002. "New Video Releases." New York Times, August 9, E26. 
Searching for Debra Winger. 2002. Rosanna Arquette, director. California: Lions Gate Home Entertainment.

Suleiman, Susan, ed. 1986. The Female Body in Western Culture: Contemporary Perspectives. Cambridge: Harvard University Press.

Tennessen, Joyce. 2002. Wise Women: A Celebration of Their Insights, Courage, and Beauty. New York: Little, Brown and Company.

Twigg, Julia. 2004. "The Body, Gender, and Age: Feminist Insights in Social Gerontology." Journal of Ageing Studies 18(1):59-73.

Warr, Tracey, ed. 2000. The Artist's Body. New York: Phaidon Press.

Whipp, Glenn. 2005. "Jack Nicholson Finally Acts His Age." Milwaukee Journal Sentinel. 1 January. Retrieved 3 October 2005, from http://www.jsonline. com/onwisconsin/movies/jan03/107424.asp.

Woodward, Kathleen. 1999. "Statistical Panic." differences 11(2):177-203.

1991. "Youthfulness as a Masquerade." Aging and Its Discontents: Freud and Other Fictions, 147-65. Bloomington: Indiana University Press.

"World Briefing: Romania, Mother, 66, and Baby Doing Well." 2005. New York Times. 18 January, A9. 


\section{Home | Books | e-Books | Journals | Books Search}

Fall 2004 New Books

Spring 2004 New

Books

Print on Demand and Back in Print Titles

About IU Press

Helping IU Press

Instructors' Page

Mailing Lists

Online Privacy

Ordering FAQ

Ordering

Information

Rights \&

Permissions

Submitting a Book

Proposal

Visit Also

\section{Indiana University Press Rights Management Site}

Welcome to the Indiana University Press rights management site. It has been designed to simplify and to speed up the process of applying for rights to reprint material from IU Press books and journals. Please note that licensing rights for our products are managed by different individuals at the Press, so be sure to click on the appropriate link below. If you are applying to reprint material from an IU Press title for classroom use, the link will take you to the Copyright Clearance Center's web site.

Once you have provided the information required and it is approved, the URL of a contract will be sent to you via e-mail. Please check the appropriate box to indicate your acceptance of the terms included in the contract and return it to the Press electronically. You will also be notified if your reprint request is denied.

- Apply for permission to reprint from an IU Press book

- Apply for permission to reprint from an IU Press journal

- Apply for permission to reprint from an IU Press journal or book FOR CLASSROOM $\underline{\mathrm{USE}}$

- For book translations and other subsidiary rights, click here.

Indiana University Press 601 N. Morton St. (812) $855-8817$ $1-800-842-6796$ iupress@indiana.edu 